\title{
Dom Quixote no teatro português
}

\section{Luiz Francisco Rebello}

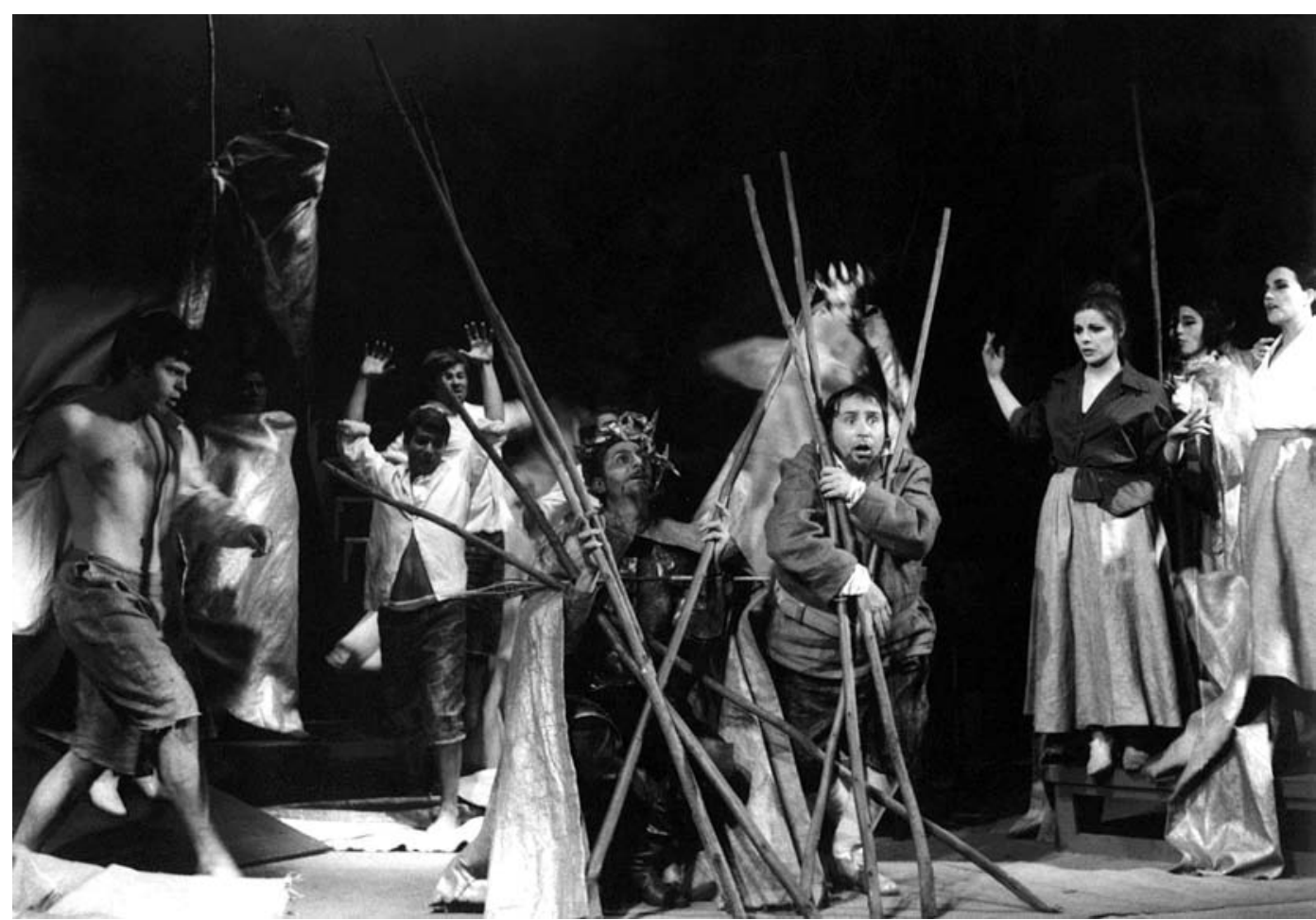

de Yves Jamiaque,

enc. Carlos Avilez, Teatro Experimental de Cascais, 1967 (Final do $2^{\circ}$ Acto), fot. J. Marques.

Assim como a personagem e as andanças do "ingenioso hidalgo de La Mancha" serviram de matriz inspiradora a compositores musicais (Salieri, Massenet, Ricardo Strauss, Falla, Ravel), artistas plásticos (Goya, Daumier, Picasso, Dali, Pomar), cineastas (Pabst, Kosintzev, Rafael Gil), era impossivel que não atraissem dramaturgos: basta lembrar as obras de Guillén de Castro, Jean Richepin, Mikahil Bulgakov, Gaston Baty, Yves Jamiaque, Alfonso Sastre, que têm Don Quijote, Sancho Panza, Dulcinea del Toboso como protagonistas. 0 teatro português não foi excepção a esta regra; como também não a poesia, de Tomás Pinto Brandão e Tolentino a Gonçalves Crespo e Gomes Leal, Pascoaes, José Gomes Ferreira e Torga.

Menos de um século havia transcorrido sobre a publicação da $2^{\text {a }}$ parte do Quijote, quando João (ou Juan) de Matos Fragoso, prolífico autor de 57 comédias ao gosto castelhano - e nesse idioma escritas, algumas das quais em colaboração com Agustin Moreto - extraiu de um episódio da novela cervantina o entremez El yerro del entendido. E numa colectânea publicada em Lisboa no ano de 1709, Musa jocosa de vários entremezes, de Nuno Nisceno Sutil, incluía-se um Entremez de D. Quijote, em verso, também redigido em espanhol, que trazia para a cena o episódio posto em música por Manuel de Falla no seu Retablo de Maese Pedro (a investida do "cavaleiro da triste figura" contra o titeriteiro que narrava com os seus fantoches o romance de Melisendra e Don Gaifeiros).

Até que, em 1733, se estreia no Teatro do Bairro Alto a "ópera joco-séria" A Vida do grande D. Quixote e do gordo Sancho Pança, primeira produção teatral de António José da Silva, "O Judeu". Dividida em duas partes, a primeira subdividida em 9 cenas e a segunda em 8, entremeada de canções, a comédia acrescenta às figuras e passos da obra originária outras oriundas da fértil invenção do autor, como o episódio em que o fidalgo manchego persegue o seu escudeiro convencido que, por artes mágicas, nele se transformou a sua amada Dulcineia. Representada por títeres (na dedicatória do autor que precede a edição do seu teatro cómico, 1744, alude-se à "alma do arame no corpo da cortiça (que) infunde verdadeiro espírito e novo alento" às personagens), e só mais tarde por actores, a "ópera" conheceu de imediato enorme popularidade; e um dos seus episódios, de que Sancho Pança é o protagonista, foi objecto de edição autónoma (cenas IV a VI da 2a parte), sob o título O grande governador da ilha dos lagartos. Nele A. J. da Silva, sem destoar do espírito burlesco da obra, formula magoadas queixas contra os rigores de uma justiça arbitrária de cuja desumana crueldade já havia sido e voltaria a ser vítima inocente: preso pela Inquisição uma primeira vez em 1726, e de novo em 1737, de ambas as 


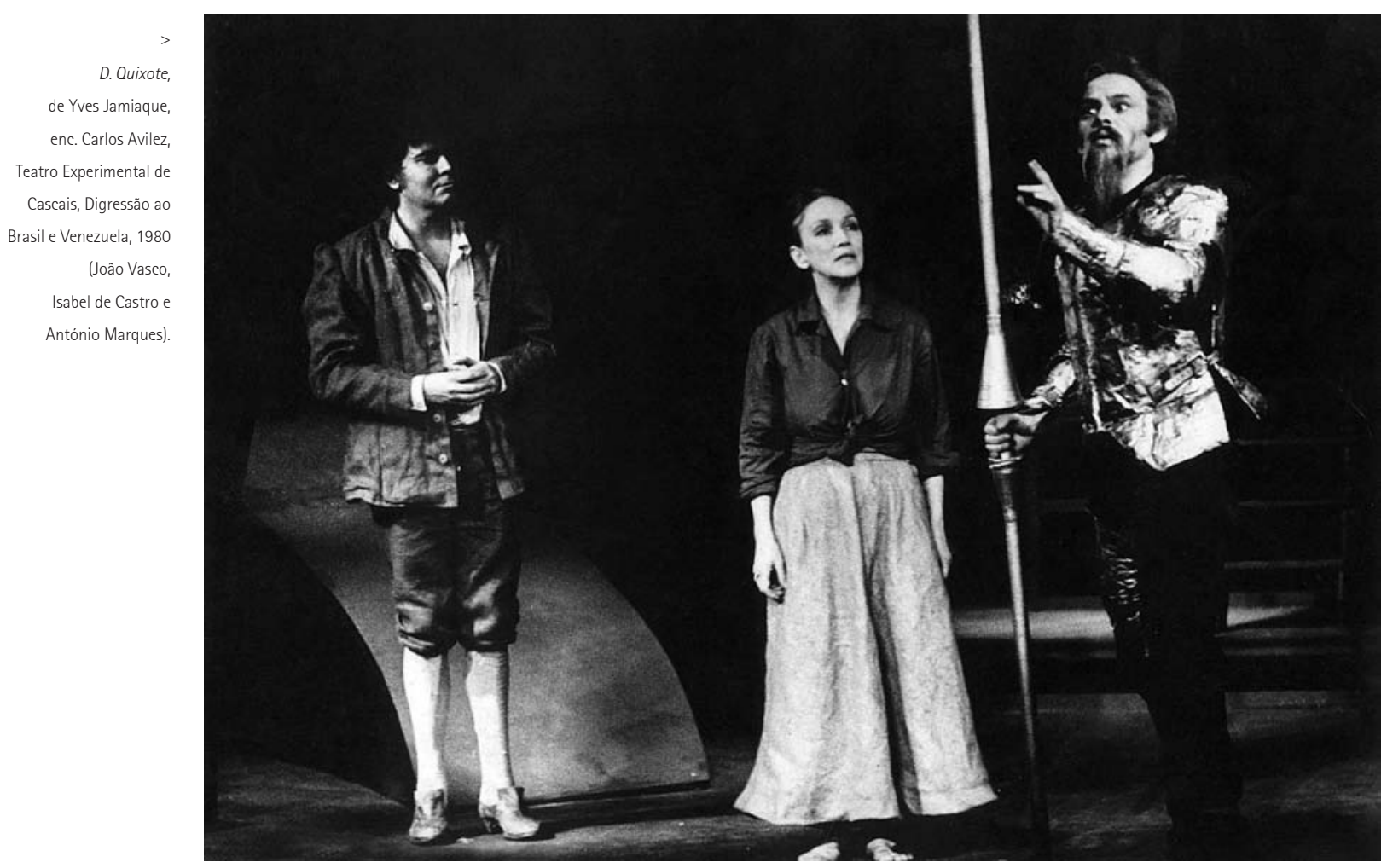

vezes juntamente com a mãe, culpado por não ter culpa ("se é culpa o não ter culpa, eu culpa tenho", dissera ele pela boca de Anfitrião, na ópera homónima) declarado "reincidente, negativo e pertinaz", consumiram-no as chamas da fogueira ateada pelo ódio do fanatismo religioso.

Já no século XIX, em 1807, representa-se no Teatro do Salitre, sempre em Lisboa, a "ficção dramática" em 1 acto de José Joaquim Leal, D. Quixote na cova de Montesinos, em que o "cavaleiro da triste figura" renuncia a Dulcineia para casar com Altizidora, disfarçada em rainha do Japão; a peça seria publicada seis anos mais tarde. Uma revista do operoso Francisco Jacobetty, estreada em 1887 no Teatro Chalet da Rua dos Condes, intitulava-se D. Quixote, "revista do ano de 1886"; e pela mesma altura Gervásio Lobato traduziu, com Pedro Vidoeira, o libreto da que fora a primeira opereta de Hervé, Proezas de D. Quixote. E só em meados do século seguinte voltaria o "engenhoso fidalgo" a ser objecto de transposição dramática no nosso país.

Por uma curiosa coincidência, é no mesmo ano - 1944 - que surgem três obras teatrais construídas sobre o tema quixotesco: Fernando Amado (1899-1968) e João de Castro Osório (1899-1970) publicam, aquele D. Quixote e o outro, este a tragicomédia 0 baptismo de D. Quixote; Carlos Selvagem (1890-1973) estreia no Teatro Nacional a "farra heróica" Dulcineia ou a última aventura de D. Quixote. A primeira é uma variação pirandelliana sobre o tema, tão caro aos autores modernistas, da pluralidade do ser; a segunda, no dizer de um crítico, "uma oratória exaltada da incomensurabilidade do Sonho"; a terceira, que deu origem a um dos mais belos espectáculos dirigidos por Amélia Rey-Colaço, com a colaboração plástica do grande pintor Almada Negreiros e musical do compositor Ernesto Halffter, dá corpo, através do contraste entre a figura do cavaleiro e os grotescos detentores do poder, ao "sonho do homem que desde o fundo das idades sofre e combate por um ideal de libertação, de redenção, de justiça social" e que, transitoriamente vencido, é retomado por outros. São estas as palavras de Jocriz, moço de cego, quando empunha a lança do derrotado cavaleiro: "cavaleiros, escudeiros e vilões! Aqui tomou suas armas D. Jocriz de Tristânia, que a sua dama fez voto de alevantar os humildes, libertar os oprimidos, socorrer os agravados e castigar toda a sorte de injustiças, violências e tiranias...". 0 entrosamento dos mitos ibéricos do quixotismo e do sebastianismo, unificados pelo sopro poético e pela exacerbação satírica, constituiu-se num dos textos mais importantes da nossa dramaturgia contemporânea, que é também a metáfora do pais carcerário que Portugal então era.

A terminar esta breve resenha da passagem do Quixote pelas páginas e pelos palcos do teatro lusitano, recordese o seu aproveitamento pelo teatro de revista (por exemplo, em Bate Certo!, 1963) e o espectáculo dirigido por Carlos Avilez sobre a peça de Yves Jamiaque, no Teatro Experimental de Cascais, com a colaboração do pintor João Vieira (1967), em que o actor Santos Manuel teve uma das suas mais notáveis interpretações. 